\title{
Fed Transparency: How, Not Whether
}

\author{
William Poole
}

C entral bank transparency is a topic discussed almost as much as policy actions themselves. Market participants have always wanted to know the implications of policy actions for the likely future course of monetary policy, but the longstanding practice of central bank secrecy has frustrated their search. In recent years, monetary policymakers have disclosed much more than they did in the past, partly because of growing interest in being more accountable and partly because of recognition that policy actions will be more effective if the market understands them better.

Discussion of transparency has gone well beyond the financial pages. The past decade has seen numerous professional papers on transparency issues. In this literature, transparency is taken to mean public disclosure, and much of the discussion has centered on questions such as: How specific should central banks be about their policy objectives? Should they announce the weights they apply to their inflation and output stabilization objectives in conducting monetary policy? Should central banks disclose their economic forecasts? Should transcripts of the policy debate be published and, if so, how soon? Should policymaking meetings be televised?

My intent today is not to review the entire range of transparency debates but instead to concentrate on issues relating to the effects of monetary policy information on markets and on the effectiveness of monetary policy. I certainly do not believe that political accountability issues are unimportant, but my chosen topic is large enough to more than fully exhaust the time available today.

Before proceeding, I want to emphasize that the views I express here are mine and do not neces-

\footnotetext{
William Poole is the president of the Federal Reserve Bank of St. Louis. This article was adapted from a speech of the same title presented at the Global Interdependence Center, Federal Reserve Bank of Philadelphia, August 21,2003. The author thanks colleagues at the Federal Reserve Bank of St. Louis for comments: Robert H. Rasche senior vice president and director of research, and Daniel L. Thornton, vice president and economic advisor, provided especially valuable assistance. The views expressed are the author's and do not necessarily reflect official positions of the Federal Reserve System.

(1) 2003, The Federal Reserve Bank of St. Louis.
}

sarily reflect official positions of the Federal Reserve System. I thank my colleagues at the Federal Reserve Bank of St. Louis - especially Robert Rasche, senior vice president and director of research, and Daniel Thornton, vice president and economic advisorfor their assistance and comments, but I retain full responsibility for errors.

My plan is to proceed by first outlining my model of how the economy works. That view is, I believe, the essential starting place for a discussion of transparency. I will then discuss two cases in which, depending on what view you have, market participants did not interpret Fed statements correctly or the Fed did not communicate clearly. Under either interpretation, there was some miscommunication.

I will use "transparency" as shorthand for accurately conveying accurate information including all the information market participants need to form opinions on monetary policy that are as complete as possible.

\section{FUNDAMENTALS OF MACROECONOMIC EQUILIBRIUM}

Analysis of policy communication logically begins with a description of the economic interaction between the central bank and the markets. I've provided my view of this interaction on several occasions; here I provide just enough of a sketch of this view to enable me to discuss communication issues. ${ }^{1}$

At a highly abstract level, I believe that the appropriate model of the economy is that markets behave in an efficient, fully informed way. Equilibrium requires that market participants form accurate expectations about the behavior of the central bank. The economy will function most efficiently if central bank policy has two features. First, the central bank must have clearly understood, appropriate, and

\footnotetext{
1 William Poole, "Synching, Not Sinking the Markets," presented before the Philadelphia Council of Business Economics, Federal Reserve Bank of Philadelphia, 6 August 1999; < www.stls.frb.org/general/speeches/ 1999_08_06_99.html > . William Poole and Robert H. Rasche, "Perfecting the Market's Knowledge of Monetary Policy," Journal of Financial Services Research, December 2000, 18(2/3), pp. 255-98.
} 
feasible objectives. Second, the central bank must have a highly regular and predictable policy rule or response pattern that links policy actions to the state of the economy, including all information relevant to assessing the economy's probable future course. Pushing the idea of a full rational expectations equilibrium one step further, there should be a political equilibrium in which the central bank pursues objectives broadly accepted in society. Without broad political support, monetary policy objectives are subject to change through normal democratic processes and such change, or the prospect of it, adds to uncertainty about future monetary policy.

With regard to objectives, the Federal Open Market Committee (FOMC) has stated repeatedly that one of its objectives is a low and stable rate of inflation. Although the FOMC has not quantified that target, for present purposes it is useful to discuss communications issues as if the FOMC had announced a specific target. Put another way, with regard to market behavior I believe that the difference between an explicit target and one inferred from FOMC decisions is minimal today and has been for some years.

The FOMC also has the objective of maximum possible stability of output and employment. Taken together, low inflation and output stability along the economy's growth path are believed to contribute to maximum possible economic growth over time. Because of its importance to output and employment stability, it is also useful to point explicitly to the objective of financial stability. Stabilizing policy responses to severe market disruptions such as a stock market crash or a liquidity crisis further contribute to fostering maximum possible economic growth.

The FOMC implements policy by setting the intended federal funds rate. As is well known, a central bank cannot achieve a stable outcome for the economy if it pegs the interest rate at an inappropriate level for any length of time. Thus, the central bank must change its interest rate target from time to time to achieve its objectives.

In my abstract model of the economy, the market and the central bank have the same information base; neither has an informational advantage. As new information arrives, the appropriate interest rate to achieve policy objectives may change. Given my assumption that the market and the central bank have the same information, all players respond the same way to the arrival of new information. The central bank determines the appropriate policy response knowing that the market also has the same information and understands its implications for the economy and for policy actions.

At a highly abstract level, I believe that this model accurately describes the way the U.S. economy has been working in recent years. As we add more and more detail to the model, we find areas in which the equilibrium is not complete. Thus, my view is that the economy has been converging toward a full rational expectations macroeconomic equilibrium, but is not all the way there as yet. In particular, over the past quarter century there has been enormous progress in improving the clarity of the Fed's objectives and in the Fed's discipline in pursuing the objectives. With regard to the inflation objective, there is a world of difference between today's situation and that prevailing in the 1970s.

There has also been enormous progress in provision of more accurate and timely information about policy actions. The FOMC announces its policy actions on the afternoon of the conclusion of each regularly scheduled meeting and promptly after any interim meeting. The Fed is more open in many other ways as well; for example, the FOMC now releases a policy statement at the conclusion of its meeting and dissents, if any, are also disclosed at that time.

My fundamental conception of the Fed's communication challenge is to further the progress toward a more complete rational expectations equilibrium. Put another way, my question is this: How might the Fed modify its communications strategy so that the market can converge on a rational expectations equilibrium with less error than we observe today?

\section{MISCOMMUNICATION-TWO CASES}

It is instructive to consider examples in which communications were less clear than they might have been and to analyze how such problems might be avoided in the future. Communications successes are also worth studying. There is a growing literature along these lines, such as analysis of the market effects of the change in FOMC practice in February 1994 to immediate disclosure of policy decisions at the conclusion of FOMC meetings.

Accurate communication is far more difficult than it seems at first glance. Complete accuracy requires that speaker and listener interpret actions and words the same way. In a normal conversation, individuals have an opportunity to clear up ambiguity by raising questions about intended meaning. It is possible to ask for clarification, or ask again, before 
acting. What central bank officials (and, of course, other officials as well) say, however, can have immediate market impact; market participants may act before ambiguities or miscommunication can be corrected. This fact imposes special burdens on central bankers.

To illustrate how difficult the communications process is in the central bank context, let me relate to you an exercise I go through at the end of each FOMC meeting. Before the decisions of the meeting are made public, I estimate-"guess" is a much better word-the market reaction to the policy action and press release that are made public at 2:15 p.m. after the meeting. Then I listen to the radio or a cable news channel to determine how the bond and stock markets respond. Ordinarily, but not always, I get the direction of the market responses correct, but my estimates of the magnitudes of the market reactions are often wide of the mark. My personal experience is that I find it exceedingly difficult to predict how people will interpret policy actions and the nuances of the press release. I suspect that other FOMC participants perform similar exercises, though I have not asked any of them.

I've sometimes thought I should keep a formal record of my market predictions, but have not yet decided to do so. It could be a sobering exercise for all FOMC members to maintain such a record. Communication is obviously imperfect if the speaker - the FOMC in this case-cannot predict accurately how listeners will respond.

Now consider two specific examples of FOMC communications that I believe were misread. The first is the evolution in the announcement of the "tilt" in the directive, and the second is the communication last May about "an unwelcome substantial fall in inflation." I emphasize that I'm offering my personal interpretation of these cases; other FOMC members may have different interpretations.

In the early 1980s the FOMC began to vote on language pertaining to possible future policy actions. This language was alternatively called the "tilt," "bias," or "symmetry" of the policy directive. The language was generally regarded as applying to possible policy action through the period ending at the next FOMC meeting. Historically, the FOMC did not release this language until the minutes of that meeting were published (subsequent to the next regularly scheduled FOMC meeting). That meant that the statement, when released, had no information value about the probable direction of policy actions because the statement referred to a period already past.
In an effort to be more transparent, the Committee decided in December 1998 that it would release the tilt language immediately with its policy action at the conclusion of a meeting when it expected the information to be particularly important. The minutes of that meeting, released in late January 1999, contain a paragraph on the Committee's discussion of a disclosure policy. A key passage from the minutes reads as follows:

Nonetheless, the members decided to imple-
ment the previously stated policy of releasing,
on an infrequent basis, an announcement
immediately after certain FOMC meetings
when the stance of monetary policy
remained unchanged. Specifically, the
Committee would do so on those occasions
when it wanted to communicate to the
public a major shift in its views about the
balance of risks or the likely direction of
future policy. Such announcements would
not be made after every change in the sym-
metry of the directive, but only when it
seemed important for the public to be aware
of an important shift in the members' views.

At the conclusion of the meeting in May 1999, the FOMC for the first time released a statement that included the "tilt" in the policy directive. The formal statement referred to "the federal funds operating objective during the intermeeting period." Many members of the FOMC believed that the market overreacted to the May tilt statement and to subsequent tilt statements as well. The statements did attract considerable attention, and market analysts began to speculate about changes in the intended funds rate at future FOMC meetings based on the tilt, or symmetry, announced by the FOMC.

The market reaction to the statement released immediately after the May 1999 FOMC meeting should not, perhaps, have been a surprise to the Committee. The Committee had said, after all, in its the minutes of the December 1998 meeting that it would make such an announcement "when it wanted to communicate to the public a major shift in its views..."

In an attempt to clarify its communications, the FOMC established a subcommittee to review both its policy directive and the public announcement following FOMC meetings. Communications practice changed in two respects. First, the FOMC would issue a statement after every meeting. That step eliminated the possibility that the mere exis- 
tence of a statement would be treated as an unusual event signaling a major change in policy.

The second step was a new "balance-of-risks" statement that assessed the outlook for price stability and sustainable economic growth in the foreseeable future. Despite the FOMC's stated intention that its new "balance-of-risks" was not to be interpreted as an indictor of future FOMC actions, the evidence suggests that it was one of the pieces of information that market analysts did use to form expectations of a likely near-term policy action. ${ }^{2}$ My perception, however, is that the balance-of-risks language did not come to have a completely settled meaning in the market.

For my second example, consider the statement following the FOMC meeting last May that referred to "an unwelcome substantial fall in inflation." In subsequent commentary in the financial press, this statement was interpreted to mean one or more of the following things: (i) A cut in the intended funds rate at the June 2003 meeting was likely. (ii) Any increase in the intended funds rate within the next year was highly unlikely. (iii) The FOMC would implement "unconventional monetary policy actions" such as aggressively purchasing long-term Treasury bonds. Interpretation (iii) gained force and a major rally in long-term Treasury markets ensued, driving the 10-year Treasury rate to a more-than-40-year low of 3.13 percent.

Speaking strictly for myself, I believe there are two important points that the statement of May 6 tried to communicate that didn't really come across. First, inflation has now receded to a level where for the first time in 40 years inflation risks are symmetric: From the current inflation rate neither sustained increases nor sustained decreases are desirable. Second, in the words of my FOMC colleague Governor Bernanke, "FOMC behavior and rhetoric have suggested to many observers that the Committee does have an implicit preferred range for inflation. Most relevant here, the bottom of that preferred range clearly seems to be a value greater than zero measured inflation, at least 1 percent or so." 3 On several occasions in the past I have stated that my

\footnotetext{
2 Robert H. Rasche and Daniel L. Thornton, "The FOMC's Balance-ofRisks Statement and Market Expectations of Policy Actions," Federal Reserve Bank of St. Louis Review, September/October 2002, 84(5), pp. 37-50.

3 Ben S. Bernanke, "An Unwelcome Fall in Inflation?" presented before the Economics Roundtable, University of California, San Diego, 23 July 2003, in La Jolla, California; < http://www.federalreserve.gov/ boarddocs/speeches/2003/20030723/default.htm >
}

preferred inflation target is zero inflation, properly measured. Since I believe that the major price indices employed today are subject to some upward bias and measurement error, the goal "zero inflation, properly measured" translates into a low, positive measured rate of inflation. In my judgment, 1 percent measured inflation for the consumption price index is in the neighborhood of price stability as I define it.

To me, though, an announcement that inflation is now down to an appropriate long-run target should not by itself have led to a sharp decline in the 10-year bond rate. What I think happened was that the market, seeing that the intended federal funds rate was down to 1 percent, thought that the Fed was running out of room to implement policy through setting a target federal funds rate. If the Fed were to switch to setting a target for long-term interest rates, then such a policy would reduce or eliminate for a time downside price risk on long-term Treasury bonds. That would justify bidding the 10-year bond price up (the rate down), because the price risk would become one-sided-bond prices could go up but not down, or at least not down by very much very soon. Over time, however, the market came to believe that the FOMC was not contemplating the need for an unconventional policy in the near term, and bond prices fell. Indeed, bond yields backed up to a level above where they had been just before the May FOMC meeting.

\section{DISCLOSURE STRATEGY}

Given my emphasis on the economic purpose of disclosure, I see no room for merely satisfying curiosity about what goes on in FOMC meetings. The general nature of what goes on in meetings can easily be inferred by reading meeting transcripts, which are released with a five-year lag. The appropriate communications goal, in the context of how the economy functions, should be to minimize market uncertainty about monetary policy. It is important to emphasize that uncertainty about future monetary policy actions cannot be eliminated because those actions depend critically on information that cannot itself be predicted. What needs to be minimized, therefore, is uncertainty about central bank responses to new information.

I'm going to concentrate my discussion on the policy statement issued at the conclusion of each FOMC meeting, but some of my comments have broader applicability. The communication at the conclusion of each FOMC meeting is a critical one because market participants are primed to react to 
news of a policy action and its rationale. The statement is necessarily short and it sets the stage for FOMC members to provide subsequent, more thorough discussions of policy. I'll concentrate on two aspects of the statement. The first is the extent to which the statement should provide a forecast in some form of future policy actions, and the second is the structure of the statement itself.

Given my rational expectations macroeconomic model and my desire to create a more complete equilibrium - an equilibrium in which expectations errors are minimized - the central communications issue is to explain to the market the nature of the policy rule that determines how new information feeds into policy actions designed to achieve as closely as possible the central bank's policy objectives. Achieving clarity with respect to policy objectives is actually quite simple compared with explaining the nature of the policy rule.

The fundamental problem is that there is no policy rule by which we can calculate the appropriate policy action from observed data. There is instead a regularity to policy of the sort "you know it when you see it."

Sometimes we observe a striking change in some particular variable, such as the unemployment rate, that all but demands a policy response. Most of the time, though, policy actions flow from an accumulation of data, most of which point in the same direction. It just is not easy to describe "you know it when you see it." I would be absolutely delighted if researchers could provide a quantified policy rule, at least as a base case. The rule suggested by John Taylor is helpful, but very incomplete. I think it unfortunate that we have not seen in the professional literature an evolution of a policy rule that builds substantially on the work begun by Taylor. But the problem is a very difficult one; for one thing, it is necessary from time to time to discount changes in an important economic variable because of suspected anomalies in the statistics themselves.

Thus, we have to live with the unfortunate fact that the monetary policy world is one of "I'll know it when I see it." We need to keep that fact in mind when designing communications policy.

Explaining a policy action-elucidating the considerations that led the FOMC to decide to adjust the intended funds rate, or to leave it unchangedis worthwhile. Over time, the accumulation of such explanations helps the market, and perhaps the FOMC itself, to understand what the policy regularities are. It is also important to understand that many - perhaps most-policy actions have precedent value. If the FOMC takes action A in circumstances $\mathrm{X}$, the next time circumstances $\mathrm{X}$ arise the FOMC should also take action $\mathrm{A}$, or have good reason not to do so. One of the advantages of public disclosure of the reasons for policy actions is that the required explanation forces the FOMC to think through what it is doing and why.

Discussing future policy actions is a different matter. In my view of the world, future policy actions are almost entirely contingent on the arrival of new information. For that reason, I believe that an FOMC forecast, or tilt, toward a specific future policy action is more likely to be misleading to the market than helpful. It is true that at the conclusion of a meeting I have a sense of the probabilities of various future policy actions, and I suspect that other FOMC members think about the policy process the same way. I might believe, for example, that new information would be very unlikely to lead me to want to raise the intended funds rate at the next meeting but might, in combination with information already known, make the case for cutting the intended rate. And I might assign a probability to a future cut of 0.5 , or 0.3 , or some other value. But even in this situation I would not want to rule out an increase in the intended rate, for I can certainly imagine new information that would compel an increase.

Question: Could the FOMC as a practical matter decide on the probability and convey that probability accurately to the market? My own view is that only rarely could the FOMC agree on what the probability should be, and even then it would be extremely difficult to convey that probability to the market. Moreover, if the probability is high, it seems to me that in most cases it would make more sense to simply take the policy action at the current meeting rather than broadcast it as likely at the next meeting.

The old "tilt" language caused problems, I think, precisely because different FOMC members had different interpretations of what probabilities attached to what words. And I think the market view was, at least sometimes, that if the FOMC chose to change the bias, it must be doing so to announce a significant probability of future policy action. I think some observers also tend to react as follows: If the probability is high, why shouldn't the FOMC act now? If the probability is low, why talk about it? If the probability is in a middle range, will disclosing the tilt help the market to price securities more efficiently - that is, more in line with the true likelihood of future policy action? 
Furthermore, the tilt language was sometimes used in an effort to reduce the number of dissents in the FOMC. In this case, the language may have provided inaccurate information, because the majority may not have believed that there was any significant probability of future policy action in the direction indicated.

Another problem is that of acting consistently with guidance about the probable direction of future policy. Sometimes new information arrives that is clearly compelling in the direction of not acting in accordance with the guidance. A forecast of a policy action, made before the new information arose, may then have created a dilemma for a central bank. The central bank then either breaks what the market regards as a commitment or lives up to the commitment at the cost of ignoring new information calling for a different policy action. However, more often information will be indecisive; once guidance is announced, the burden of proof tends to shift toward showing why the forecasted action is inadvisable, whereas without guidance the burden of proof tends toward justifying an action.

All in all, then, I've come to the view that FOMC language forecasting future policy actions is probably counterproductive in most circumstances. I do not, however, rule out the desirability of forecasting future policy in some cases given that the rational expectations model from which I am reasoning is clearly an abstraction. What I think we need to do is to analyze the circumstances under which the abstract model provides misleading guidance with respect to communications strategy.

It is true that policy works in part by changing expectations and therefore the term structure of interest rates; that is the basic argument favoring disclosure of future policy direction. However, the crux of the matter is this: If the market fully understands the policy rule, or policy regularity, and has the same information the FOMC has, then an FOMC forecast of future policy direction is useless information because it is redundant. If the market and the Fed have the same information, then the market can determine the probabilities that new information will arrive pointing toward future policy actions. Understanding policy objectives and the policy rule, the market can put itself inside the Fed's head and make the same guesses the Fed can make.

If information on the Fed's thinking about its future policy direction is not redundant, then that fact alone does not necessarily call for the Fed to forecast future policy actions. The issue for me is quite different. If the market doesn't see what I see, why not? What is the market missing, and what do we make of the fact? Perhaps the better course would be to disclose the underlying information the market is apparently missing, or call attention to information the market is neglecting. That to me is a better strategy than hinting at an unconditional policy direction, because the essence of what the market needs to know is not the intended federal funds rate in six weeks. What the market needs to know is the policy response function by which the central bank acts in a consistent way over time and one that is efficient in fostering success in achieving policy objectives.

This discussion assumes that the market is missing something. But, could the problem be that the market sees something I do not? How can I be so sure that I know the appropriate direction for future policy actions? If it is the Fed that is missing something and not the market, then disclosing a policy tilt will clearly be misleading, or the odds are that it will turn out to be misleading.

Historically, the FOMC (and other central banks) went to great lengths to avoid providing guidance about future policy direction. Indeed, one of the arguments that the Fed used in the defense of secrecy in the Merrill case in 1975 was that the immediate release of the information in the directive or in FOMC deliberations would produce expectations that would destabilize financial markets. That argument is incomplete at best. Some disclosures clearly stabilize rather than destabilize markets; secrecy can create incorrect market guesses about what the Fed is doing. One such case arose on Thanksgiving eve 1989, when the Open Market Desk intervened to supply reserves for technical reasons. At this time there was no announcement of the intended funds rate. The intervention was widely interpreted by market participants as a signal that the FOMC had reduced its target for the federal funds rate from around 8.50 to about 8.25 percent. It took several trading days before the market sorted out the confusion. On this occasion secrecy produced unnecessary volatility in financial markets. Numerous other examples provide convincing evidence, in my view, that, in general, disclosure of actual policy actions is stabilizing rather than destabilizing. But it is not appropriate to generalize from the value of immediate disclosure of policy actions to disclosure of "everything."

To discuss the format of the policy statement at the conclusion of each FOMC meeting, I'll start with an observation. Suppose the statement is confined 
to one page. With even those few words, the richness of language and the importance of word order in conveying meaning yield the result that the statement contains an enormous range of possibilities. The multiplicity of possible meanings is made even larger since each statement is read against the backdrop of the previous one. Thus, what is relevant is not just word choice and order but changes from the previous statement.

As an aside, the importance of statement changes can make it difficult to improve the statement over time. To avoid misinterpretation of changes, it is best if a changed approach or format can be announced in advance so that the change in approach is clearly separated from a change in policy.

If the statement is to convey policy intent accurately and with minimal ambiguity - surely desirable characteristics in terms of minimizing expectational errors in the market - then the number of possible meanings must be narrowed in some way. One way would be for the FOMC to chose among a relatively few standard phrases, at least in language providing a summary statement of the policy stance.

Some will regard this approach as providing "boilerplate" language with little real meaning. My own judgment is that it is better to provide boilerplate with clear meaning than rich language with a multiplicity of possible meanings. It just is not true that lots of words equals lots of disclosure and greater transparency.

Because the market responds immediately to policy actions and statements, it is important that the FOMC not find itself in the position of having to clarify its statements to correct misinterpretations; explaining the explanation can add to uncertainty and raise questions about future policy statements, which market participants might come to expect to be clarified or interpreted. The best way to avoid these problems is to narrow the range of phrases used in the statement.

As I explained earlier, my view is that the statement should concentrate on explaining the policy action and its rationale, and not hint at future policy actions. Given information available at the time of a meeting, I believe that the standing assumption should be that the policy action at the meeting is expected to position the stance of policy appropriately. The purpose of the statement should be to explain why the policy action, or lack of action, has positioned policy appropriately given the information available.

As a matter of logic, the current balance-of-risks language creates some ambiguity. If risks are assessed as unbalanced, why was policy not adjusted further to create a balance going forward? A possible answer is that an unbalanced risk assessment foreshadows future policy action. But the "tilt" interpretation of an unbalanced risk assessment seems at odds with the rationale for substituting the balance-of-risks language for the previous tilt language. What would be clearer, I think, would be to use the balance-ofrisks language to explain that information since the previous meeting indicated that risks were becoming unbalanced in a particular way, and for that reason the FOMC adjusted the intended federal funds rate.

Separating growth risks from inflation risks, as in the May statement, makes a lot of sense. When employment change and inflation data are plotted in a scatter diagram, all four quadrants contain lots of observations. Sometimes employment and inflation rise together, or fall together. However, just about as often the two variables move in opposite directions. Because all four quadrants are populated, a summary policy judgment has to be communicated indicating the FOMC's weighting of the risks. It is relatively easy to explain that a policy tightening was occasioned by a rising risk of higher inflation and stronger employment growth; but when employment growth and inflation are headed in opposite directions, the summary policy language needs to indicate that the FOMC acted, or didn't, because it gave more weight to the inflation risk than the employment risk, or vice versa. The issue is not, by the way, that inflation risk is more or less important than employment risk, but rather that current information might suggest that recent employment changes, say, are transitory.

This discussion makes clear that a minimally accurate summary statement explaining a monetary policy action is still pretty complicated. The FOMC must weigh inflation risks, employment risks, and form a judgment balancing or weighting the two risks. Beyond that, from time to time special factors will intrude, such as the tragic events of 9/11 or unusual liquidity crises.

\section{CONCLUDING OBSERVATIONS}

Transparency is a worthy goal, but improving transparency is hard work. My thinking is still evolving, but one thing I know is that the more I consider the issue the harder it seems.

I've tried to present a framework for thinking about how to improve transparency. I start with a view of the world based on a standard rational 
expectations macroeconomic model. An efficient equilibrium requires that the markets understand what the central bank is doing. The communications challenge for the central bank is to explain more thoroughly and completely what it is doing. That means, above all, explaining how new information feeds into policy actions. I have a lot of skepticism about forecasting future policy actions because they properly flow from new information that is not itself predictable.

Accurate communication requires settled meanings for words. For any given word, we can consult a dictionary and we usually discover that each English word has several meanings, which can be quite different. There is no dictionary in which we can look up the several meanings of a paragraph. The meaning of a policy statementpreferably only one-must be established by the central bank, through consistent practice over time and through more extended discussion of what the language means.

I think it fair to say that systematic study of the how of transparency is in its infancy, and I hope that my remarks here spark others to analyze these issues. 